Session 1660

\title{
Performance Comparison of US and Thai Engineering Students under Similar Learning Conditions
}

\author{
P. Rusmee \\ Sirindhorn Institute of Technology, Thailand.
}

\begin{abstract}
Comparative study of two groups of engineering students, one from the United States and one from Thailand, was conducted. Their performance and their behavior were compared to show the differences or similarities that may not be obvious when only a few students from one group is placed with the other group, i.e., foreign students in a US classroom situation. The US sample group was from solid mechanics classes taught at the University of Utah, USA from 1994 to 1997. The Thailand group was from the solid mechanics classes taught at Sirindhorn International Institute of Technology (SIIT), Thailand from 2001 to 2004. Both groups were subjected to similar teaching and learning conditions. It was found that the Utah group performed better than the SIIT group in all grading categories, i.e., assignment, exam, and project. The differences can be attribute to the age, level of expectation, and cultural conditioning. Understanding the root causes of the differences in performance of the two groups can help US-base engineering educators deal with "foreign" students more effectively.

Introduction

Instructors in a US engineering school will invariably have non-American students in their classes at some point. Certain behaviors and standard of conducts exhibited by these nonAmerican students may seem strange to some. At times, they may even do something that is clearly not acceptable by US standard of conduct. The number of students in this category is usually too small to warrant further examination as to the root cause of the behavior. They are simply an anomaly and are dealt with as such, on a case-by-case basis. Seeing how these students perform and behave in their "native" environment can yield a great insight into reasons behind many of the observed behaviors. This way, the root cause of what perceived to be a problem can be dealt with effectively.
\end{abstract}

This study is a report on observations of two groups of students, one at the University of Utah, USA and the other at Sirindhorn International Institute of Technology (SIIT), Thailand. Specifically, they were students taking a second year, mechanical engineering course in solid mechanics. As many variables such as textbook, instructor (the author), teaching method, etc., were kept as close to being the same as possible. The data from the Utah group were complied from classes taught between 1994 and 1997. The SIIT group included the data from classes taught starting in 2001 up to 2004. 


\section{Demographics}

Before making any performance comparison, it would be informative to examine the make up of the students in these two groups. Table 1 lists some demographic information regarding the gender and the residency status of the students. The word "native" for the Utah group refers to those students who speak English as their first language. On the other hand, the word "native" for the SIIT group refers to students who are Thai nationals.

The profile of the SIIT group, in terms of age, is very typical of Thai students. There are usually a very small percentage of non-traditional students in Thai universities. Students start college right after they finish their secondary education at the age of 18 . The average age of the students, when they took the class in this study, was 19.6. The oldest student was 23 and 17 for the youngest. Most students were at the age typical of sophomore students who started college right after high school. The number of male to female students was also typical of an engineering program such as this. For this SIIT group, male students outnumber female students $86.6 \%$ to $13.4 \%$.

Thai students account for $96.8 \%$ of the students in the SIIT group. The rest of the $3.2 \%$ were mostly foreign exchange students with only 2 out of 198 students were foreign nationals who were fulltime matriculate students. Disregarding the exchange students the percent of foreign students dropped to $1.1 \%$. It can be said that the SIIT group was a very homogeneous group in terms of age and cultural background.

Demographic profile of the Utah group was not as exact as the SIIT group. It was derived from 1999 data published by the University of Utah. ${ }^{1,2} 55.7 \%$ of the students were incoming freshmen while the rest were transfer students. It was assumed that the data from this source did not change appreciably in the span of years covered in this study. This aggregate data was for the entire university where the make up, especially the gender, can be quite different from those of engineering students. From the aggregate data, $53.5 \%$ of the students were male, $46.5 \%$ female. Assuming that the mix remained unchanged, the percentage for engineering students differed markedly from the general university population. In the actual Utah sample group, only $10.3 \%$ of the students were female.

The average age of the students at the time of entry were 20.9 years. A majority of the students, $50.6 \%$, was between 18-19 years of age with the oldest being older than 55. Allowing for the second-year class being examined here, the age of the students would be 21.9 when they took the class. In addition, Utah is unique among universities in the US in that many male students of

Table 1 Profile of students from the two student groups used in this study.

\begin{tabular}{|c|c|c|c|c|}
\hline \multirow[t]{2}{*}{ Average age } & \multicolumn{2}{|c|}{$\begin{array}{c}\operatorname{Utah}^{1,2,3} \\
>21.9 \text { (estimate) }\end{array}$} & \multicolumn{2}{|c|}{$\begin{array}{l}\text { SIIT }^{4} \\
19.6\end{array}$} \\
\hline & Count & $\%$ & Count & $\%$ \\
\hline Male & 70 & 89.7 & 161 & 86.6 \\
\hline Female & 8 & 10.3 & 25 & 13.4 \\
\hline Native & 65 & 83.3 & 180 & 96.8 \\
\hline Foreign & 13 & 16.7 & 6 & 3.2 \\
\hline
\end{tabular}


LDS faith take leave for 2-year missions. When they return to the university, they often start over with a different major than what they started out with in the freshmen year. Within this subgroup, the age when they take the class could easily be three years more than the estimated age of 21.9.

With the younger average of SIIT students comparing to the Utah counterpart, the financial and family situation were also different. $100 \%$ of the SIIT students attended school full time. $100 \%$ of the students did not work either full time or part time to pay for school. The costs of their education were shouldered almost entirely by parents. Very few scholarships were available to students as SIIT was not part of a government-supported university system. The Utah group, on the other hand, had a more heterogeneous mixed of students. They are a mixture of single student similar to the SIIT group to student who was married with children and a full time employment going to school part time or a combination there of.

Number of foreign students in engineering is also quite different from the general student population. Foreign students account for $1.98 \%$ of the overall incoming student. The actual percentage of foreign students in the Utah group was $16.7 \%$. This agreed with a generally accepted perception that foreign students tend to go into science and engineering fields. This large percentage of foreign students is significant enough to warrant extra effort on the instructor's part to understand how they function.

The male/female students' ratio did not differ significantly between the Utah and the SIIT groups. The percent of female students were slightly larger in the SIIT group, 3\% more, even without any special effort to recruit female engineering students. In certain engineering disciplines such as industrial engineering or computer science, the percent of female students approaches $50 \%$. From an informal information gathering, Thai females were less resistant to becoming engineers because of math and science requirements. Being "dirty" and heavy physical demand were the two main reasons why female students shied away from engineering. When they did choose engineering, they chose the engineering disciplines that were deemed "cleaner" and less physical demanding.

There was no formal entrance examination at the University of Utah in the time span covered in the study. On the other hand, SIIT requires an entrance exam score from one of many acceptable "entrance exams." However, the entrance exam requirement is more of a formality at SIIT because almost all of first tier universities in Thailand require an entrance exam. In effect, both Utah and SIIT have similar open admission practice. After being admitted to the university, Utah engineering students must pass their first year of study before applying for an intermediate status. SIIT student choose their field of study after completing their first year of study. In this regard, both groups of students had gone through similar steps by the time they became part of this study.

\section{Course structure}

English was used as the language of instruction for both groups. It was one of SIIT mandate to produce engineering graduates with adequate English proficiency to work in international work environment. All lectures and interactions with the students in the SIIT group were done in English. By the time the SIIT group took the class considered in this study, they would have had at least one full year of full time instructions conducted in English. 
The solid mechanics course in this study was a required, second year mechanical engineering course at both institutes. This course was also accepted as equivalent course for some other major at Utah. As such, the make up of students by major were different from the SIIT group. There were a mixture of mechanical engineering, civil engineering, and architecture majors in the classes. For the SIIT group, $100 \%$ of the students were mechanical engineering major.

Both groups were instructed in typical lecture class environment. The major difference was in the class size. The Utah group averaged 26 students per class while the SIIT group averaged 66 students per class for the total of 78 and 198 students respectively. The primary reason for this was due to the SIIT course being offered only once a year while the Utah class, at that time, was offered four times a year. Utah students had the flexibility of tailoring their class to suit their need and level of readiness. The "cohort" system at SIIT did not afford the students that flexibility. If a student missed a class offered for his group, he risked having to take an additional year to complete his study.

The course was a second-year course in solid mechanics. The Utah course was taught under quarter system while the SIIT course was in semester. The content of both courses, however, was approximately the same. In effect, the SIIT group had five more weeks to learn approximately the same course content. Lecture periods were also different. Utah group had three 50-minute periods of lecture per week. The lecture time for the SIIT group comprised of two 80-minute periods per week.

The textbook used at Utah was Beer and Johnston, Mechanics of Materials, $2^{\text {nd }}$ edition. Newer edition of the text was used at SIIT. It was Beer, Johnston, and DeWolf, Mechanics of Materials, $3^{\text {rd }}$ international edition. While there were certain differences in the two editions of the book, the topics covered in the courses did not differ appreciably from edition to edition.

Grading was based on exams, weekly assignments, and one term-length project. Three exams (two midterms and one final) were given to the Utah group versus three midterms and one final for the SIIT group. The exams were one hour long, four problems for the midterms and double the time and number of problems for the final exams. Average homework assignments were 3-4 problems per class period. Almost all homework was assigned from the textbook. Extra assignments dealing with design or numerical analysis were given throughout the term. In addition to regular assignment, students were required to do a term-length, design project. The nature of the project was to perform a design analysis of either a newly designed or an existing object. The weighting factor for the final grade differed slightly from term to term. The exams normally account for roughly $50 \%$ of the final grade with the other $50 \%$ divided up between the weekly assignments and term project. Grading curve was used to assign the final grade. In affect, the students were competing among themselves not a fixed grading criterion.

Performance comparisons

Table 2 lists the performance of the two student groups in terms of three grading categories and overall grade. On average, the Utah group performed better than the SIIT group. The class average for the Utah group was $74.8 \pm 12.1 \%$ with the range of 95.2 to 43.0 percent. The SIIT 
group performed almost 20-percentage point below the comparable Utah group. The average for this group was $56.5 \pm 15.4 \%$ with the high of $96.6 \%$ to the low of $15.6 \%$.

The lower average performance score of the SIIT group posted no problem with the students. They were accustomed to lower class average than the American counterparts. While 56.5\% average might be low by American standard, it was seen as on the high side of the $50 \%$ average expected by the SIIT students. The minimum score for both groups also show this disparity, $43.0 \%$ for the Utah group versus $15.6 \%$ for the SIIT group. The difference could be accounted for by the minimum graduation requirement. The students in the Utah group were required to have $\mathrm{C}$ grades or better to have the class counted toward graduation requirement. On the other hand, SIIT only required a passing grade. In addition, the SIIT group appeared to be more detached or have higher tolerance to low score than the Utah group. It would take a much lower score for the students to take notice and try to improve their grade situation. They were more likely to ask for leniency and better grade after the fact.

Similar trend on the low end could be seen in other grading categories as well. The difference, however, is less obvious in the assignment scores. The weekly assignment was more of a measure of the students' immediate understanding of the lectures and textbook instead of deeper understanding of the subject. While the average assignment score of $62.3 \pm 18.5 \%$ was lower in the SIIT group, the difference of $9.1 \%$ is well within one standard deviation. The differences between the two groups in this grading category may not be as significant but it is noticeable nonetheless.

On the other end of the spectrum, there was always some student achieving near perfect score in class. Both Utah and SIIT groups were equivalent in this regard. The maximum score in each category was in the high ninety percentile. The near perfect similarity between the two groups showed that the best students would always be able to perform similarly well regardless of other external factors.

Perhaps the most glaring difference between the two groups was in the applied engineering component of the course. The design project was where the students had an opportunity to demonstrate that they were capable of applying the knowledge they learnt in classroom setting to a "real world" problem. The Utah group showed a much higher competency in this regard. The lowest scoring student in the Utah group was more than $40 \%$ higher than the SIIT counter part.

Table 2 Performance comparisons for students taking solid mechanics class at University of Utah and Sirindhorn Institute of Technology.

\begin{tabular}{lcccccr}
\hline & \multicolumn{3}{c}{$\begin{array}{c}\text { Utah } \\
\%\end{array}$} & & \multicolumn{3}{c}{ SIIT } \\
& avg & $\max$ & $\min$ & avg & $\max$ & $\min$ \\
\hline Exams & $73.5 \pm 14.9$ & 95.8 & 23.5 & $52.9 \pm 15.4$ & 99.2 & 16.8 \\
Assignments & $71.4 \pm 14.8$ & 99.7 & 24.6 & $62.3 \pm 18.5$ & 98.0 & 19.4 \\
Project & $92.8 \pm 10.2$ & 100 & 50.0 & $63.9 \pm 19.7$ & 100 & 9.5 \\
Overall & $74.8 \pm 12.1$ & 95.2 & 43.0 & $56.5 \pm 15.4$ & 96.6 & 15.6 \\
\hline
\end{tabular}


The difference in the performance in the "applied" aspect of the class could be attributed to the difference in the curriculum structures. Utah group put more emphasis on design and applied engineering from the very first course prospective engineering students took. Students had opportunities to perform engineering designs and analyses even when their engineering knowledge was in its infancy. Their enthusiasm seemed to be higher by the time they were given such assignment in higher lever courses.

For the SIIT group, it was the first design project they were ever assigned. There were a lot of anxiety and uncertainty involving the processes and expectations. Up until this point, their classroom experience and expectation had been limited to learning from the lectures and textbooks. Their performance evaluations were based on their "book" knowledge instead of their abilities to apply that knowledge. Even when this difference in learning emphasis putting the SIIT group at a disadvantage, some students were able to overcome it and performed admirably well in the design project. The maximum score of 93\% from the SIIT group compared well with the $100 \%$ of the Utah group. However, their disadvantage was still obvious as their design performance was only more comparable to the "average" of the Utah group.

The difference in design aptitude should not be thought of as an indication of the quality of the students but rather the difference in teaching emphasis. The SIIT teaching system, as with most Thai universities, places more emphasis on memorization and understanding of text materials with less emphasis on creativity or hands on practice. The benefit of this approach is that the students are more familiar with specific cases, equations, or examples. The disadvantage is that the student is unable to apply the knowledge more effectively. However, this inability to applied engineering knowledge should not be viewed as permanent. After the initial "shock" of different set of demands putting the SIIT group, the students seemed to embrace the design and hands on aspect of the class just as enthusiastically as the Utah group. With persistent on the instructor's part, the difference should diminish.

It may be said that students' nationality will affect the class performance since the ability to understand the language of instruction would play a big part in students' performances. The assumption of nationalities affecting performance, while true to some extend, is not entirely accurate since students prior familiarity of the language and the teaching methods may not be classified effectively by the nation of origin or residency status. The foreign students in the Utah group were a mixture of US and foreign educated students. Those who graduated from a US high school system, thus more familiar with the instructional environment, performed indistinguishably from the "English speaking" students.

There was no significant number of native English speaking students at SIIT that could be used for comparison with the Utah group to see how they would function in Thai learning environment. $100 \%$ of foreign and Thai students spoke English as a second or third language. However, their prior secondary school experiences were quite diverse. Most of them had gone through traditional Thai secondary schools, some attended "international" schools where the curriculum was modeled after the US or UK educational systems. A small percentage even graduated from high school overseas. Twenty out of 198 students $(10.8 \%)$ in the SIIT group graduated from "international" schools in Thailand or high schools overseas before attending 
SIIT. As such, the level of English competency among the students in the SIIT group varied widely. There were students who were able to conduct themselves perfectly in English in and outside of class. There were also students who could not understand enough English to function well in class even after a full year in an English-immersion learning environment.

While the inability to understand the language of instruction hampered the class performances for the students on the lower end of the group, the inverse was not necessary true for students at the other end of the spectrum. If such were the case, students who had better command of the language would have performed better than the rest of the group. These students' English competency did not give them, as a group, any clear advantage over the rest of the students. Their performances ranged from near the top to the middle of the class.

There was one problem that was very prevalent in the SIIT group but almost unheard of in the Utah group, plagiarism. Students often copied each other assignments and represented them as their own. Written reports that were copied verbatim from various sources were common. This type of activity is not unique to SIIT. It is common among Thai students and seems to be common among students from certain region of the world.

There are two main reasons that could explain the prevalent plagiarism activities among the SIIT students. One is opportunity and the other is tendency. The average class size of 69 students makes it difficult to adequately overseeing every student to the degree that would eliminate all or almost all opportunities to plagiarize. Students would then have opportunities to submit copied works with little chance of being detected. Extra vigilant in the instructor's part in grading and detecting copied works does curtail this type of activities, even by the most persistent of the perpetrators.

Another reason for plagiarism practice among the SIIT lies in the cultural tendency. There is a tendency to think of ownership to be of objects and things not abstract concepts or ideas. Ones can clearly own an object that can be touched and demonstrate his ownership by putting the object away. Owning ideas or intellectual work is more abstracted. Ones cannot touch or feel such abstraction or put it away completely once it has been shown. This way of thinking is also applied to the way students share their works. Discussions of assignments or ideas among themselves are not seen as sharing. Instead, it is the giving of the finish work, on paper, diskettes, etc. that is considered as sharing. They are not sharing ideas but they are sharing the object representing those ideas. This does not mean that reappropriating something own by another is condoned. It would be considered wrong to simply take the paper the assignment was written on and put a different name on it. That would be considered stealing because an object, the paper, is wrongfully taken away from the owner. However, copying the assignment onto another piece of paper is acceptable because no ownership changes hands.

Education effort can be made to explain the concept of ownership of abstract ideas to students. It would be reasonable to assume that the plagiarism incidences would reduce. Many students who engaged in such practice were doing it out of ignorance rather than malicious intents. Experience with some foreign student in Utah who engaged in the practice seemed to support this point. 
Another cultural difference that could account for the different performance level is family support. The entire SIIT group did not have to work to pay their way through school. There was less personal incentive on the student's part to learn as much as possible. Fortunately, students seemed to take more personal interest in their education as they progress through the program.

There was also a difference in the level of student participation in and outside of class. The Utah group, as a whole, interacted more with the instructor during class. They were also more likely to seek consultation outside of class time. The same could not be said of the SIIT group. They were very passive and timid in class most of the time. Interactions in class were limited to the instructor lecturing to the group of listening students. Outside interaction was also limited. They rarely, if ever, seek consultation outside of class. Instead, they preferred private tutorial school for helps. The exceptions were those students whose prior educations were at an international school or high school overseas.

The explanation for passive participation by the SIIT group is again cultural. Teachers are held in high regard in Thai society. It is considered impolite to interrupt a teacher during lecture. To some extend, it is even considered a taboo to openly question the validity of the knowledge being taught by the teacher. This image of a teacher has been perpetuated and reinforced throughout the education system where typically large class size makes active student participations impractical. Those students educated under the "international" system did not exhibit as much timidities or disconnectedness as those educated under the traditional Thai system. However, their level of participation improved slightly once they understand that active participation is expected.

This study only compared the percent ranking of the two student groups in the most similar learning environment as feasible. Even so, an attempt to compare the two groups based on GPA is not possible. Thai universities tend to have problem with grade deflation. It is not unheard of for the person who graduate first in his class to have a GPA close to 3.0 or honor at graduation bestowed to students with GPA as low as 2.5. SIIT has a strictly enforced minimum class GPA guideline of 2.0. The class GPA for the SIIT group in this study was in according to the institute guideline. For the Utah group, the class GPA was 2.33 or a $\mathrm{C}+$.

Despite the many differences that put the SIIT group at a disadvantage when they are compared to the Utah group, they tend to do quite well after graduation if prior graduating classes are any indication. Very high percentage of students continues to pursue higher degrees. For example, $46.6 \%$ of the class of 2001 graduates follows such course. ${ }^{5}$ Universities in Germany and United Kingdom were the favorite choices among SIIT graduates. United States, Japan, and Australia were also mentioned frequently. There were not enough of SIIT graduates returning from pursuing higher degrees to draw any conclusions at this point. However, early indication seems to indicate that they performed comparably to other overseas graduate students.

It is tempting to make comparisons among students from different countries by comparing statistics such as graduation rates, etc. Such direct comparisons may be too simplistic. Other factors, i.e., social, economic, political, etc., must be considered. For example, Thai students may be under more pressure to conform and graduate with their peers within four years in the field they had first chosen while American students may not be subjected to such pressure. As a result, 
the American students can take more time to explore different fields of study and take more time to complete their degrees if at all. ${ }^{6}$ Discussion in this paper is based more on qualitative comparison between to sample groups based on the author's experience. To make a more valid quantitative comparison, a more rigorously planned study will have to be conducted. However, there will always be some unquantifiable factors that cannot be eliminated when two very different cultural groups are compared. Certain statistics that may be unacceptable to one group may as well be a norm in the other.

\section{Conclusions}

Two different groups of students from two different universities in two different countries were taught in a similar manner, as much as possible, so that performance comparisons can be made. The Utah group generally bested the SIIT group in all evaluation categories. This discrepancy could be due to the age, prior conditioning, learning expectation, cultural norm, etc., that were quite different.

The Utah group was older and more mature as a whole. Some of them already had family responsibilities or had to shoulder the cost of education themselves. The SIIT group showed less maturity simply because were younger and more dependent on parental support for their education.

Plagiarism practice among the SIIT students may be due partly to the difference in concept of intellectual ownership. Extra effort on the instructor's part to explain the acceptable standard of practice can overcome the problem. The instructor should not assume that the students in his or her class are already familiar with standard and practice of the US schooling system.

The lack of familiarity of American style of teaching where the emphases are placed on learning and hands on practice is proven to be a big disadvantage to the SIIT group when it is a factor in performance evaluation. Whether this disadvantage can be overcome could not be answered within the span of a single course covered in this study. There is evidence that it can be improved judging from the receptiveness of the SIIT group after they have adjusted to the "new" learning expectation.

Expectation of lower score on the SIIT part is expected to continue. No solution to the lower performance expectation is offered because it is not seen as a problem but simply a different in judging expectation. In the end, the student will be graded on a curve meaning they are graded on their performance relative to their peers. The question of what constitute an acceptable percentile ranking is irrelevant.

\section{References}

1 Institute Analysis, http://www.admin.utah.edu/ia/studentprofiles/traditional1999.htm.

2 Institute Analysis, http://www.admin.utah.edu/ia/studentprofiles/transfer1999.htm.

3 P. Rusmee, Final Grade Report, Office of the Registra, University of Utah, 1994-1997.

4 Academic Record, Sirindhorn International Institute of Technology.

5 Annual Report, Academic Year 2002, Sirindhorn International Institute of Technology, Thammasat University. 

Online, February 17, 2004.

\section{Biographical Information}

P. RUSMEE: P. Rusmee was a graduate of University of Utah. He is currently, at the time of writing, an assistant professor in the Mechanical Engineering Program at Sirindhorn International Institute of Technology, Thailand.

SIIT is an independent engineering institute in association with Thammasat University, which is one of the top-tier universities in Thailand. 